\title{
Delayed Inhalational Injury due to Accidental Muriatic Acid Poisoning
}

\author{
Dr. Kavuru Naga Siri \\ General Medicine Department, Sree Balaji Medical College and Hospital, Chennai, India \\ Dr. Suresh Kanna \\ General Medicine Department, Sree Balaji Medical College and Hospital, Chennai, India \\ Dr. K. Shanmuganadan \\ General Medicine Department, Sree Balaji Medical College and Hospital, Chennai, India
}

\begin{abstract}
Muriatic acid is the commonly used toilet bowl cleaner in India. It is delivered industrially and is utilized for cleaning, pickling, electroplating metals, in refining mineral metals, in petrol well extraction, in cowhide tanning, in the refining of fats, cleansers, and consumable oils. Inhalation is the most common exposure of muriatic acid contamination. In this article, medical studies about a case of delayed inhalational injury due to muriatic acid poisoning has been reported.
\end{abstract}

Key words: Safety, Inhalation Injury, Acid Gas, Acid poisoning

\section{INTRODUCTION}

Muriatic acid is the commonly used toilet bowl cleaner in India. It is delivered industrially and is utilized for cleaning, pickling, electroplating metals, in refining mineral metals, in petrol well extraction, in cowhide tanning, in the refining of fats, cleansers, and consumable oils. Inhalation is the most common exposure of muriatic acid contamination.

Inward breath is a significant course of exposure to any gas poisoning and same may also cause Acid Poisoning by exposure to Acid Gas.

\section{The Case History}

A 37-year-old male patient sanitary worker by profession, came to the OPD with complaints of difficulty in breathing and chest discomfort of 2 hours duration. On direct inquiry he gave history of accidental inhalation of toilet cleaner while working in his office 2 days prior to onset of symptoms followed by exposure to fumes of bathroom cleaner. He also complained of palpitations, headache, nausea. He had no co morbid illnesses. His blood pressure is $130 / 90 \mathrm{~mm}$ of $\mathrm{Hg}$, pulse rate of $96 / \mathrm{min}$ and respiratory rate of $26 / \mathrm{min}$ sp02 was $90 \%$ on room air. Examination of respiratory system revealed bilateral crackles at both lung bases. Other systemic examination was unremarkable.

Investigations showed complete blood picture as normal and chest $\mathrm{x}$ ray had bilateral non homogenous lung fields. ABG respiratory failure type 1 . Patient was managed with antibiotics and treated symptomatically.

\section{Acid Gas and Fumes}

Hydrogen chloride is a dreary, destructive, nonflammable gas that exhaust in air with sharp scent. Hydrogen chloride isn't ingested through the skin, yet when hydrogen chloride gas interacts with dampness, it structures hydrochloric corrosive, which is destructive and can cause disturbance and consumes.

Inward breath is a significant course of exposure. Its fume is heavier than air and may cause suffocation in encased, ineffectively ventilated, or low-lying zones. Youngsters presented to similar levels as grown-ups may get bigger portion since they have more prominent lung surface area. Standards and Guidelines: promptly hazardous to life or wellbeing $50 \mathrm{ppm}$. Practically everything people could be presented for as long as 1 hour without encountering or creating irreversible or other genuine wellbeing impacts or manifestations which could hinder a person's capacity to make a defensive move $20 \mathrm{ppm}$. Brief openness to $35 \mathrm{ppm}$ causes throat bothering, and levels of 50 to $100 \mathrm{ppm}$ are scarcely okay for 60 minutes. The best effect is on the upper respiratory plot; openness to high fixations can quickly prompt expanding and fit of the throat and suffocation. Most genuinely uncovered people have quick beginning of fast breathing, blue shading of the skin, and narrowing of the bronchioles. Patients who have monstrous openings may build up a gathering of liquid in the lungs. Openness to hydrogen chloride can prompt Reactive Airway Dysfunction Syndrome (RADS), an artificially or aggravation-initiated sort of asthma. After intense exposure, aspiratory work by and large revisitations of benchmark in 7 to 14 days. Albeit complete 


\section{Yinternational Research Journal}

p-ISSN 2202-2821 e-ISSN 1839-6518 (Australian ISSN Agency)

recuperation is normal, manifestations and delayed pneumonic shortages can persevere. Patients may create Reactive Airways Dysfunction Syndrome (RADS).

\section{The Exposure}

Exposure of the eyes to concentrated hydrogen chloride fume or hydrochloric corrosive can cause corneal cell passing, waterfalls, and glaucoma. Openness to weaken arrangements can cause stinging agony and wounds, for example, ulcers of the eye surface.

Exposure or delayed openness to hydrogen chloride has been related with changes in pneumonic capacity, persistent aggravation of the bronchi, nasal ulceration, and manifestations looking like intense viral disease of the upper respiratory parcel just as irritation of the skin, staining and disintegration of dental polish, and aggravation of the eye film. Chlorosis may happen with delayed openness.

Muriatic corrosive isn't ingested through the skin. Direct contact with fluid arrangements of hydrogen chloride or with concentrated fume can cause serious substance consumes. Ingestion of concentrated hydrochloric corrosive can make extreme destructive injury the lips, mouth, throat, throat, and stomach, dying, hole, scarring, or injury arrangement, torment, trouble gulping, queasiness, and vomiting. Liver harm and ischemia might be observed. Renal disappointment and nephritis may happen. Ingestion of concentrated hydrochloric corrosive or huge skin openness to either hydrochloric corrosive or hydrogen chloride gas may cause low circulatory strain because of gastrointestinal draining or liquid relocation.

\section{V.Discussion}

The determination of intense hydrogen chloride harmfulness is basically clinical, considering side effects of the destructive activity of the gas or corrosive. All normal examinations to be done. If respiratory-parcel disturbance is available, screen with chest radiography and heartbeat oximetry (or ABG estimations).

There is no cure for hydrogen chloride harming. Treatment comprises of help of respiratory and cardiovascular capacities. Positive-pressure, independent breathing mechanical assembly is suggested accordingly circumstances that include openness to conceivably dangerous degrees of hydrogen chloride. If the patient is seriously uncovered Quickly access for a patent aviation route, guarantee satisfactory breath and heartbeat rate. Control supplemental oxygen as required. Flushing of
Vol. 11 No. 022021 828011022021161 (C) Author(s)

uncovered eyes with lukewarm plain water or saline for 15 minutes.

Administration of supplemental oxygen by veil to patients who have respiratory side effects treating patients who have bronchospasm with aerosolized bronchodilators ought to be finished. Consider the soundness of the myocardium prior to picking the type of bronchodilator ought to be regulated. Cardiovascular sensitizing can be possible.

\section{CONCLUSION}

As prevention is better than cure, it is suggested that use of safety precautions and switching over to non-irritant disinfectant is preferable in any case of exposure to Acid Gas and Acid Poisoning and in any such case an immediate healthcare support is advised.

\section{REFERENCES}

[1]. (NIOSH) National Institute for Occupational Safety and Health. Criteria for a recommended standard: Occupational exposure to nitric acid. Springfield (VA): National Technical Information Service; 1976. DHEW (NIOSH) Pub No. 76-141; NTIS Pub No. PB 81-227-217. [Google Scholar]

[2]. Lee-Chiong TL., Jr Smoke inhalation injury. Postgrad Med J. 1999; 105:5562. [PubMed] [Google Scholar]

[3]. Hajela R, Janigan DT, Landrigan PL, Boudreau SF, Sebastian S. Fatal pulmonary edema due to nitric acid fume inhalation in three pulp-mill workers. Chest. 1990; 97:487-9. [PubMed] [Google Scholar]

[4]. Meduri GU, Golden E, Freire AX, Taylor E, Zaman M, Carson SJ, et al. Methylprednisolone infusion in early severe ARDS: Results of a randomized controlled trial. Chest. 2007;

131:95463. [PubMed] [Google Scholar]

[5]. Sadegh Soltan-Sharifi M, Mojtahedzadeh M, Najafi A, Reza Khajavi M, Reza Rouini M, Moradi M, et al. Improvement by $\mathrm{N}$-acetylcysteine of acute respiratory distress syndrome through increasing intracellular glutathione, and extracellular thiol molecules and anti-oxidant power: Evidence for underlying toxicological mechanisms. Hum Exp Toxicol. 2007; 26:697-703. [PubMed] [Google Scholar] 


\section{Manuscript Processing Footprints}

\section{A. Journal Volume/Issue Details}

This manuscript it published in Vol. 11 No. 022021 issue of IARS' International Research Journal (I'IRJ).

This is a Peer Reviewed (Refereed) International Journal published by IARS' Press Australia (International Association of Research Scholars) The Volume/Issue is a regular issue of the journal published in August 2021 Available at: https://researth.iars.info/index.php/curie.

\section{B. Copyright, License, and Publishing Rights}

- $\quad$ IARS' Press Australia (International Association of Research Scholars) respects the rights of the authors of research content published with IARS' International Research Journal. The "First Publication Rights" (FPR) to the original work accepted for publication at IARS' International Research Journal is granted to the Publisher of the Journal but copyright for all work published in the journal is retained by the author(s). Works published in the Journal is distributed under a Creative Commons Attribution 4.0 International License (CC BY 4.0). (This license lets others distribute, remix, adapt, and build upon your work, even commercially, as long as they credit you for the original creation. This is the most accommodating of licenses offered. Recommended for maximum dissemination and use of licensed materials.)

- After publishing the content with IARS' International Research Journal, the author holds complete right on the content for its amendments and reuse in any form. IARS' International Research Journal confirms that author(s) holds the copyright of the content.

- Author(s) grant(s) permission for their work to be indexed in part/full form in commercial and non-commercial indexes. Author(s) grant(s) permission for their work to be harvested in part/full form in commercial and non-commercial archives and distributed through them. Author(s) grant(s) permission for their work to be translated in part/full form in any language and republished and redistributed. Author(s) may enter into separate, additional contractual agreements for the non-exclusive distribution of the published version of the work, with an acknowledgement of its initial publication in this Journal.

- It is the responsibility of the author(s) to secure all necessary copyright and/or permissions for the use of third-party content in their manuscript(s). Author(s) have declared the same at the time of submission of manuscript and 'may also be required' to provide written evidence of this permission anytime in case required for any purposes.

- Publications Ethics and other Terms and Conditions as mentioned on official website of IARS' International Research Journal.

\section{Last Plagiarism Report}

Settings: Similarity of 09 words in a row has been considered plagiarized.

Plagiarized (7\%)

Unique (93\%)

\begin{tabular}{|l|l|}
\hline Date & Aug 13, 2021. \\
\hline Words & 74 Words Plagiarized / Total Words 1072. \\
\hline Source & 2 Source(s) Identified. \\
\hline Remarks & Low similarity detected, check your supervisor if changes are required. \\
\hline
\end{tabular}

Exemption / Relaxation by Editor: None

\section{Processing Track}

\begin{tabular}{|l|l|}
\hline Date of Submission & 10 April 2021 \\
\hline Date of Final Review & 28 July 2021 \\
\hline Date of Acceptance \& Schedule & 15 August 2021 \\
\hline Date of Publishing & 29 August 2021 \\
\hline
\end{tabular}

